\title{
TMT Diversity Outcomes Under Environmental Contexts: A Review of Literature and Research Agenda
}

\author{
Victor M. Muithya ${ }^{1} \&$ James M. Kilika ${ }^{1}$ \\ ${ }^{1}$ Department of Business Administration, School of Business, Kenyatta University, Kenya \\ Correspondence: James M. Kilika, Department of Business Administration, School of Business, Kenyatta University, \\ Kenya.
}

Received: January 12, 2019

Accepted: February 26, $2019 \quad$ Online Published: February 28, 2019

doi:10.5430/jms.v10n1p43

URL: https://doi.org/10.5430/jms.v10n1p43

\begin{abstract}
The construct of Top Management Team (TMT) has received a significant attention in the strategic management scholarship due to the espoused role that TMT members are expected to play in providing direction to their organizations. In this role, they are expected to make strategic choices that optimize the opportunities availed by the rapidly changing environments. The theoretical underpinning for TMT and the extant empirical work have demonstrated a number of issues that call for further examination of the extant literature. In this paper, the authors explore the conceptual, theoretical and empirical literatures on TMT Diversity to establish the current state that accounts for the identified issues and identify the emerging knowledge gaps that set an agenda for future research. The paper identifies the various forms of TMT Diversity, the intermediate and ultimate outcomes as well as the potential influence of these outcomes by the aspects of industry velocity in which firms operate. Several theories that complement the role of the upper echelons theory are discussed and the constructs they contribute to in explaining TMT Diversity outcomes identified. The paper proposes a theoretical model for explaining the emerging phenomenon from the deployment of TMT Diversity and makes several propositions. The paper calls on future research to consider the proposed framework for adoption in empirical work.
\end{abstract}

Keywords: TMT diversity, strategic choice, environmental characteristics, industry velocity, firm performance

\section{Introduction}

Organizations experience variations in performance due to instability in their business environments and markets which call for a proper leadership and governance so as to drive the organization's quest for sustained superior performance. The required system for governance and leadership is provided by the collective Top Management Team (TMT). Hambrick and Mason proposed the upper echelon theory in 1984 to address various issues affecting the top management teams within firms. According to Zaccaro (2001) the TMT generally is in charge of the organizational purpose and direction which is the backbone of any firm. The TMT drives the firm towards attaining its goals by making strategic choices on performance at the corporate level. According to Ackermann and Eden (2011), the TMT membership for most organizations are mostly composed of seven to ten members who bear the expectations of the stakeholders as the symbolic bearers of the firm's vision, mission and direction who must exert effort in order to sustain goal achievement against a myriad of complex challenges.

Members of a TMT possess different characteristics that account for different forms of diversity.TMT diversity thus refers to the variation in the characteristics among members of the TMT. The characteristics are divided into two broad forms; demographic characteristics and psychological characteristics. The demographic characteristics are observable and include gender, ethnic, age, education level, functional background and team tenure. Psychological characteristics are unobservable and they include locus of control, emotional stability and self efficacy. The differences in characteristics of the TMT should be used towards achieving the end state of every firm which is sustained and improved firm performance. To achieve firm performance the TMT must make strategic choices directed towards the desired goals of the firm.

Formulation of strategies is one of the key duties of the TMT in ensuring implanting of an effective strategic management process which calls the TMTs to make decisions that enable the firm to properly fit in its environment. An important component of the firm's strategic management process is that of making a strategic choice. Strategic choice involves the continous process of making decisions in an environment of uncertainty. Firms do not operate in 
vacuum and thus they need to scan the environment into detail. TMTs decide on strategic choices that are aligned towards the overall performance of the firm. The process of decision making involves selection of alternatives among different choices. The strategic choice should be made on the basis of the option that offers maximum utility to the firm. The prevailing external environmental characteristics as well as the firm's internal characteristics have been found to demonstrate a contingent effect on the relationship between TMT diversity and firm performance (Haleblian, \& Finkelstein, 1993). Internal environmental characteristics include firm age, managerial practices and institutional processes. External characteristics include institutional pressures, and firm velocity (Geletkanyez \& Hambrick, 1993). Thus, diverse TMTs in organizations make strategic choices for their firms in the context of their dynamic environments to optimize achievement of desired performance.

\subsection{Statement of the Problem}

The Construct of TMT Diversity is one that upon deployment in a strategic management process involves a diversity of phenomenological outcomes that scholarship needs to address. It has been associated with aspects that have to do with decision making and information processing and likely to face influence from the context in which the TMT operates (Bunderson \&Sutcliffe, 2003; Canella, Park \& Lee, 2008). On the one hand, the literature fails to demonstrate its link with decision making as well as how it connects with the context in which the decisions have to be made and the information to be obtained from. The phenomenon it brings about attracts other constructs that the literature is yet to demonstrate how they connect with the construct such as the decision outcome of strategic choices and the nature of the context in which the decisions are made (Child, 1997; Tony, 2000).

In addressing the challenges in the phenomenon it brings about in organizations, the phenomenon requires input of multiple theories that stem from diverse disciplines that scholarship needs to tap into so as to bring about a more clear understanding of the role of TMT Diversity in strategic management. However, in examining this multidisciplinary based literature, the existing disciplinary boundaries seem to have hindered the possibility of integration of the constructs in informing scholarship in strategic management. For example, the concept of TMT has attracted a variety of descriptions that have not been integrated into a complete set of constructs matched with their indicators for empirical investigation and therefore much of the literature remains scattered (Kinuu, 2014). Secondly, the conceptual literature on the context of TMT Deployment touching on the concepts of industry velocity and the outcome of strategic choice shows high complimentarity that needs to be synchronized into models that link TMTs with firm strategic behaviors. Thirdly, these concepts attract diverse theoretical descriptions that go beyond the prescriptions of the upper echelon that needs to be tapped into so as to enrich the extant knowledge in strategic management touching on TMTs and subsequent outcomes in organizational processes.

The previous attempts to conceptualize some of the constructs associated with the phenomenon emerging from the deployment of TMTs demonstrate several weaknesses. For example, attempts towards understanding TMT Diversity have taken a bias towards the demographic dimension and given little attention to the psychological dimension that is gaining prominence due to the role played by managerial cognitions (Nadkarni \& Narayanan, 2007; Nadkarni \& Barr, 2008). Those that have focused on the construct of velocity have taken a narrow perspective that has not considered it from the totality of all its dimensions (McCarthy, et.al 2010). The construct of strategic choice is one that has not been clearly operationalized and its linkage with TMT not well articulated even though existing evidence from the literature abounds on its nature and how it is an aspect of top management decision making in response to the external conditions that the organization faces (Tony 2000; Child 1972; Child 1997). The limitations cited in the literature have been blamed for the kind of decisions TMTs have made, how they have made the decisions and the impact of the decisions on corresponding firm performance (Tony 2000). The extant empirical work that has leaned on the current understanding has also produced mixed results and has not been mounted on the basis of a comprehensive consideration of a broad range of theories and constructs (Geletkanycz \& Hambrick 1997; Nutt \& Wilson, 2010).

In order to address the issues raised from the literature, scholarship needs to examine the work so far done so as to make suggestions on necessary improvements to enrich the milestones achieved. The authors suggest that the starting point is by examining the existing diverse literature to understand the conceptualization, identify conceptualization gaps and complementarities existing from both the conceptual and theoretical literatures. This would require a consideration of the diverse conceptual literature, extant theories that anchor the constructs and state of researches so far completed. This will offer an opportunity to respond to the gaps that have led to criticisms on the state of the literature and provide a way forward in informing future research work. Thus, the purpose of this paper is to examine the extant literature on TMT Diversity, with a view to consolidating the current understanding on the phenomenon it brings about upon deployment in organizations in the context of their dynamic environments. The paper first 
generates the conceptual literature on the construct and those that characterize the phenomenon it brings about, identifies issues arising and reviews the relevant theoretical literature that underpins the constructs. Secondly the paper identifies the emerging issues that need to be addressed and finally suggests a theoretical framework for guiding future research.

The current paper is done in view of several considerations that give it relevance not only in management but also in practice. The paper appreciates the multidisciplinary orientation to strategic decisions that have to be made in organizations and the need to provide a theoretical base that is broadly informed. The paper responds to the emerging need to address the limitations that have characterized conceptualization of the concepts of TMT Diversity, strategic choice and industry velocity by drawing from extant literature that even though appears rich, yet remains widely scattered. By relying on the contributions of Child (1997), McCarthy et.al (2010) and Tony (2000), the authors respond to the gaps identified in their work to consolidate a rich repository of knowledge for application in strategic management.

Secondly, in line with the multidisciplinary orientation, the construct of TMT is one that needs to be addressed from a broad based theoretical perspective. In scouting through the literature, the authors identify a wide range of theories that are relevant to underpin constructs that feature in the strategic management phenomenon brought about by the deployment of TMT Diversity. Such theories are found in contributions by scholars in organizational studies and industrial psychology. By drawing from contributions spread across multiple disciplines, the contributions of the paper enrich the existing literature in strategic management as well as enhance its relevance for practice and empirical work.

Finally, the paper proposes a theoretical model for guiding future empirical work. An important concern in strategic management is that of performance. Some of the criticisms against the extant literature have been on the TMT decision making regarding strategic choice and how it has been responsible for poor performance of organizations (Tony 2000). This paper has responded to this criticism by consolidating the literature on the conceptualization of the construct and tied it to theoretical work that has linked strategic choice to the conditions of the external environment. By doing so, the authors provide a comprehensive perspective to the construct of strategic choice in a way that guides the practice by TMT members so as to address the inherent challenges that have been responsible for poor performance in organizations.

\section{Review of Literature}

In response to the study objectives, the paper aims at presenting a summary of the construct of TMT diversity with a view to highlighting its outcomes at several levels of analysis in the context of changing business environments.

\subsection{Top Management Team Diversity}

The concept of TMT diversity has its roots in the Upper Echelons theory by Hambrick and Mason. Menz (2012) defined top management team as senior executives in a firm who are responsible for one or more functional areas. Traced from upper echelons foundations by Hambrick and Mason, the various types of TMT diversity as applied in strategic management agree that TMT diversity is the variation in observable and unobservable characteristics of the top management team, broadly classified as demographic and psychological respectively. To understand TMT diversity it is important to address the two differences in diversity; demographic and psychological characteristics. Many researchers have tried to address the issue with various differences for the various indicators. Cyert and March (1963) were the initial proponents of the essence of TMT in their study on dominant coalition in 1963. Other proponents who emphasised on TMT diversity as it evolved were Hambrick and Mason in 1984.They generally grouped TMT diversity aspects into two broad categories, namely, demographic and psychological forms of diversity (Hambrick \& Mason, 1984).

\subsubsection{Demographic Diversity}

Demographic forms of TMT Diversity are the observable characteristics of the TMT. They include; gender, age, education, functional back ground, team tenure and team size.

Bunderson and Sutcliffe, (2003); Canella, Park and Lee (2008) posited that functional background was an important source of skill and expertise and therefore, it influenced the manner in which information was retrieved and exchanged to make decisions. In addition Brouthers and Nakos, (2000) assessed functional background as having a great relation to experience. This experience helps in making sound strategic decisions through scanning the environment and being creative diversity in the education is a key aspect of TMT diversity. 
Hambrick and Mason in 1984 argued that education was an indicator of an individual's attitude, skills and knowledge and it was related to team's information processing capacity. Higher levels of education were related to innovation according to Wiersema and Bantel, (1992). Education diversity brings about varied skills and knowledge and thus growth of the firm if used positively. It can also lead to disagreements among the TMT hence affecting strategic decision making.

Age heterogeneity is the variation in age number among the TMT. It is measured by calculating the coefficient of variation of the TMT age differences (Murray, 1989; Richard \& Shelor, 2002; Tihanyi, Ellstrand, Daily \& Dalton, 2000). A high variation score was associated with age heterogeneity while a low score indicated age homogeneity. Richard and Shelor (2002) further postulated that age was a substitute to belief systems, networks affiliations and perspective of the TMT and also associated greater age differences among the TMT to increased firm performance. They highlighted on the tendency of older managers focusing more on risk aversion and conservatism unlike younger managers, which generally makes them more prone to achieving performance results that are in conformity with industry norms. Having a synchronisation among the TMT of different ages is a complex issue.

Team tenure is an indicator of TMT diversity as well. Katz, (1982) operationalised team tenure as the duration of time that team members have worked together. It brings about cohesiveness, which is "glue" against break up. Myriad researchers have associated long-tenured groups with high degree of mental rigidity and commitment to the status quo, standard ways of communication and conservative strategies adhering to those in the industry (Bantel \& Jackson, 1989; Katz, 1982; Finkelstein \& Hambrick 1990). Short tenured firms are not stable strategically in their performance. Cohesion is a key element of unity in purpose towards attaining firm goals.

TMTs size is defined as the number of senior executives involved in coming up with strategic decisions within firms at the corporate level. They make key decisions on strategic issues affecting a firm. Even though there was positive relationship between TMT heterogeneity and group size according to research by Allison, (1978) but according to Curral, Forrester, Dawson and West, (2001), yet larger firms had poor team processes and hence minimal firm performance. Thus, the size of TMT can enable both faster and slower decision making. It is not easy to have consensus among different team members all the time.

Gender diversity is the equitable or fair representation between genders. Gender is socially constructed by the society according to Frink, Robinson, Reithel, Arthur, Ammeter, Ferris and Morrisette, (2003). There was a positive relationship between gender diversity and firm performance, always if the gender bias is balanced, (Frink et al, 2003). Gender diversity helps in dealing with conflict resolution, adaptation to change and integration according to research by Krishnan and Park, (2005). Men and women have different capabilities in decision making and work performance. Women TMTs are more people-oriented, more democratic and consultative, and more inclined to interpersonal relations which contributes to firm performance as highlighted by Bolla, Brown, Eldreth, Tate and Cadet, (2002).

\subsubsection{Psychological Diversity}

The school of thought on TMT psychological diversity has paid attention to the Psychological characteristics that are unobservable indicators of TMT diversity. Even though psychology both as a discipline and construct is broad, the studies supporting this school have narrowed to three aspects of psychology, which the behavioral science stream of management has cited as essential components of human personality (Robbins, 1986). The aspects are: self efficacy, locus of control and emotional stability.

Self-efficacy is defined by Bandura (1996) as people's judgment of their capabilities to organise and execute courses of action so as to attain designated types of performance. It influences one's goals, effort to expend, perseverance and strategies and it is dynamic in nature. Research by Maertz, Bauer, Mosley, Posthuma, and Campion (2005) on self efficacy found out that self efficacy had a positive relationship with firm performance and human behaviour. TMTs with high self efficacy face challenges in a better way compared to those with low self efficacy. Experience and social persuasion lead to growth of self efficacy among the TMT.TMT with more experience and high persuasion capabilities are associated with great performance.

Locus of control is defined as what an individual perceives as the main causes of events in life. The locus of control index was developed by psychologists in 1954 under the concept of control psychology. Individuals are either internals or externals depending on what they believe to control their destinies. Rotter (1966) identified externals as being controlled by luck, chance or fate. Spector (1982) and Kinick and Vecchio (1994) further posited that internals are more committed to their respective firm than externals. This makes them more productive than the externals. Thus, in establishing TMTs, an effort should be made to ensure that the composition tends towards mostly internals. 
McCrae and Costa, (1987) defined emotional stability as having a state of anxiety, compulsion, defense and thin skin. Having a stable emotional state is important for making strategic and concrete decisions. Further studies by Bass (1990) posited that the most successful leaders are emotionally stable and emotional stability is positively correlated with TMT social integration and it influences response to problems.

This discussion on the nature of TMT Diversity brings out three implications that the authors are the view that need attention in understanding how its deployment will shape organizational phenomenon typical of firm strategic behaviour, namely the decisions arising from the functioning of TMTs, the impacts of the functioning of TMTs and their decisions and the external setting in which TMTs function and make the decisions. The decisions TMTs make revolve around making choices that give direction to firms and the intention of the choices is to impact the prosperity of the firm in line with the defining characteristics of strategic decisions (Pearce \&Robinson, 1997; Hofer \& Schendel, 1978). It is therefore proper within the context of strategic thinking to delineate this choice and the intention of the choice as constituting the outcomes of the deployment of TMT Diversity that can be understood as intermediate and ultimate outcomes. The intermediate will correspond to choice while the ultimate to performance. The strategic thinking orientation underscores the role of the external environment whose developments avail both opportunities and threats that TMTs need to respond to. Of particular concern is the manner in which the opportunities emerge and disappear which has been addressed in organizational studies through the construct of velocity (McCarthy, et.al, 2010; Nadkarni \& Narayan, 2007). The literature shows that this aspect of velocity will play a role in the manner TMTs make their decisions such that they will be perceived to be of good quality (Oduour $\&$ Kilika, 2018). We therefore suggest that the constructs of strategic choice and industry velocity need consideration in the attempt to explain how deployment of TMT Diversity explains firm strategic behaviour. This will open an avenue to tap into the rich repository of knowledge in organizational studies where these concepts have been sufficiently studied and import such knowledge to enrich the theory, conceptualization and practice of strategic management. Thus in the ensuing sections, the study provides discussions on the constructs of strategic choice, firm performance and industry velocity.

\subsection{Strategic Choice}

The construct of strategic choice is of relevance to the phenomenon emerging from the deployment of TMT Diversity due to the nature of strategic management that derives from Strategic thinking as both a concept and way of thinking. It is a process rather than an event, because it involves a number of stages, as opposed to being a one spectacular event. Strategic choice is one of the stages in strategic management which involves selection of alternative courses of action with an aim of adapting to the environment and having an edge over competitors. Decision-making process involves the continuous gathering of intelligence, direction setting, option identification, strategic choice and implementation (Mintzberg, Raisinghani \& Theoret, 1976).

Strategic Choice involves an evaluation of options so as to select the best course of action that is favourable to the firm. The selected course of action should be unique, achievable, cognizant and acceptable. In addition, strategic choice is developed from the consideration of the firm's environment, organizational capabilities and its current competitive position (Biggadike, 1991). Through strategic choices, firms come up with strategies which are considered a road map for the firm and that require the TMT actions and interactions. In spite of its role and importance to firms, there is still much that remains undocumented about strategic choice regarding its very nature, what it entails and theoretical underpinnings. Child (1997) and Tony (2000) have attempted a response towards this direction.

Tony (2000) approached the construct from the background of experiences in practice that have led to poor performance of organizations drawn from the choices due to management myopia leading to adoption of strategies that do not work, have difficulties in injecting learning, commitment to the past and failure to manage stakeholders and their agenda. Thus he proposed the need to adopt a more balanced approach to strategic choice guided by a consideration of the current environment and situation, future competitive advantage in a way that would lead to strategic options that lead to strategic breakthroughs and continuous improvement which ultimately lead to stronger performance.

Strategic choice process can be described in terms of the whole process through which a decision is taken to choose a particular option from various alternatives using diverse methods and in consideration of the internal and external environments. The most critical part is that where a team has to make a final choice on the most optimal option where a decision for final choice is taken considering the various parameters in mind. Some of these parameters could be feasibility, prudence, consensus, and acceptability. The Strategic Choice process can then be summarized to comprise intent, analysis, option generation and choice selection. Under the intent, the decision team considers what 
the organization wants to achieve and become which is reflected in the vision statement and corporate objectives. In the analysis, teams carry out a situational analysis involving both internal and external factors to understand the situation faced by the company that requires a strategic response. Undertaking this leads to generation of viable options that a firm can consider so as to enter into the analysis for consideration for adoption. Each of the options generated must prove to be authentic in that it represents a viable option; believable in that it is supported by evidence; communicable in that it is understandable and deliverable in that it can be executed.

Tony (2000) proposed a five point criteria to guide on how the choice is arrived at so as to strike the balance found missing from previous literature and practice. The five point criteria are based on:

- Strategic attractiveness: which is assessed on the basis of present market growth, market volatility, competitive intensity, future market growth, fit with own capability, likely to edge over competitors.

- Financial attractiveness: assessed using incremental sales volume generated, premium pricing achieved, discounts avoided, costs reduced, costs avoided, accelerated or retarded strategy development, share price impact.

- Implementation difficulty: evaluated based on inherent complexity, clarity of implementation structure, determination and commitment, resistance, availability of resources and skills.

- Uncertainty and risk: which assessed through environmental uncertainty, management uncertainty, cultural uncertainty

- Stakeholder acceptability: based on management opportunities, attractiveness, skeptism and threats to career development

\subsection{Industry Velocity}

TMTs make decisions within the confines of the external context of their firms. One of the influencing factors to the decisions TMTs make is that of industry velocity. Industry velocity originated from the construct of environmental velocity that was suggested by Eisenhardt and Bourgeois (1988) from their studies in strategic decision making in the micro computer industry. The concept has been adopted in strategic management and organizational theory where it has been considered as representing the rate and direction of change of the notional space in which an organization exists. The space referred to implies the macro environment factors of political, technological, economic and competitive forces of the environment that influence an organization. It has been studied from both disciplines to suggest the role it plays in firm survival in that firms need to adjust their activities to suit the state of environmental velocity since firms that do so will have a competitive advantage over those that do not.

Industry velocity has been defined as the rate at which new opportunities emerge and disappear in an industry (Nadkarni \& Narayanan, 2007; Eisenhardt \& Martin, 2000). The velocity of a firm is determined by the stability and resistance to shock. Eisenhardt and Bourgeois (1988) considered industry velocity to fall into two categories, low and high. High industry velocity environment exhibits rapid and discontinuous change in demand, competition, technology and regulations. A low velocity firm has a stable environment while high velocity firms are characterized by turbulent and complex environment (Keck, 1997). Low velocities firms are characterized by long hours spend on searching for information on the market, growth potential and economic conditions. Large firms have easy access to information as compared to smaller firms. Low-velocity firms are characterized by low rates of new product introductions, technological changes and competitive actions; competitive advantages are neither easily created nor destroyed. There is minimal competition in these low velocity firms. Low velocity firms have smaller capability of going global. International experience as highlighted by Athanassiou and Nigh (1999) highly affected high velocity firms than low velocity firms.

This categorization has implications for strategic management practice in organizations in terms of decision making. On the one hand, one stream of research has established that success in high-velocity environments is related to fast, formal strategic decision-making processes and the use of heuristic reasoning processes. On another perspective, research attributed to Nadkarni and Narayanan (2007) has examined the link between firm collective cognition and perceived environmental velocity. The focus has been trying to understand how the collective beliefs and associated practices of a firm shape how members of the firm perceive the velocity conditions of the environment. The researchers found that environmental velocity is not simply an external and objective condition to which firms react; rather, firms collectively construct their environmental velocity through their social networks, collective assumptions, and environmental scanning approaches (Nadkarni \& Narayanan, 2007). They thus advised firms to employ adaptive scanning and sense making approaches to effectively understand and deal with the dynamism in high-velocity environments. 
In order to take care of the comprehensive nature of the construct of velocity, McCarthy et al. (2010) proposed a framework that considers both the rate and direction of change across the various dimensions composed of both rate and direction of change across multiple dimensions (e.g., regulations, demand, product, technology, and competition). The framework attempts to describe the relationships between these multiple velocity dimensions, noting that they may each have a distinct and often different velocity. They proposed the concepts of velocity homology and coupling. They defined "velocity homology" as the degree to which velocity dimensions have similar rates and directions of change and "velocity coupling" as the degree to which the velocities of different dimensions affect one another. This multidimensional treatment of environmental velocity results in four "velocity regimes" - simple, divergent, conflicted and integrated - based on the patterns of velocity homology and velocity coupling. A key implication of the framework is that firms should not necessarily focus on being uniformly fast (or slow) to suit industry conditions. Each of the four velocity regimes requires firms to maintain different forms of temporal fit (i.e., the entrainment of multiple organizational paces) and temporal coordination (i.e., managing the interdependences between organizational paces).

\subsection{Firm Performance}

Performance is the actual achievement of goals against the desired or planned goals or objective by a firm. Connolly, Conlon, and Deustch, (1980) defined firm performance as the satisfaction of stakeholders. It is how the firm manages its performance to match its corporate and functional strategies and objectives. Satisfaction of firm stakeholders is mostly through profits, growth and market value. The measurement of firm performance has evolved recently with several measurement frameworks and methodologies such as; balanced score card, the performance prism, economic value added, economic profit, activity based costing and self assessment techniques (Neely,1999). Firm performance is mostly seen as the barometer of firm success. The performance of firms can be measured in terms of efficiency as suggested by Garcia-Sanchez, (2010). This is because the main mission of firms is transformation of inputs into outputs, which entails efficiency as measured by the ratio of inputs to outputs (Oakland, 2000) so as to indicate the manner in which resources have been utilized in attaining firm goals. When the performance of a firm is good, the firm grows and the stakeholders are satisfied, which is part of the strategic management process. There are various different measures of firm performance which are broadly described as financial and strategic perspectives. Strategic management field in analyzing firm performance has greatly borrowed from the finance and economic fields.

The Financial perspective to performance has used indicators that include profitability, growth and market value. Profitability is measured by various indicators like; Return on Assets (ROA), Earnings before Interest Tax Depreciation and Amortization (EBITDA), Return on Investment (ROI), net income/revenues, return on equity or economic value added. Growth indicators include market-share, asset growth, net revenue, net income or number of employees' growth. Strategic performance is measured by various factors; benefits management, portfolio management, risk management, critical success factors and program management. They help in detecting any variations from the expected and having action plans for such variations according to (Sanchez \& Robert, 2010). These indicators are not easily tangible, quantifiable and realizable.

Over and above the financial and strategic dimensions of performance, a variety of stakeholders are also interested in measurement that reflects internal and external customer satisfaction represented by employees and external customers respectively. Customer satisfaction increases the willingness-to-pay as posited by Barney and Clark, (2007).The various indicators of customer satisfaction from myriad researches include products and services mix, number of complaints, repurchase rate, new customer retention, general customers' satisfaction; numbers of new products/services launched. Satisfaction of employees is indicated by investments in human resources activities according to studies by Harter, Schmidt, and Hayes, (2002). It is important to have the employees who are involved in transformation of inputs into outputs satisfied. The satisfaction of these stakeholders translates itself into a firm's ability to attract and retain employees and lower turnover rates, according to Chakravarthy (1986). Myriad researchers have identified various employee satisfaction indicators like employee turn-over, career development and training, wages, salaries, and rewards policies, organizational climate among others.

\subsection{Conceptual Issues}

The conceptual literature reviewed raises several issues. First, is the level of consensus that various scholars who have attempted to describe each have been able to reach. While diverse perspectives are discernible from the approaches the scholars have proposed, there is relatively high degree of consensus on the current understanding of the constructs out of which several indicators that operationalize each are clearly identified. Alongside this consensus is the multidisciplinary based perspective that the concepts seem to draw from. For example, in discussing diversity, the authors draw majorly from a behavioral science background that has undertaken to study the components of both 
demographic and psychological forms of diversity as individual behavioral determinants that are classified as independent variables in influencing organizational behavior at the individual level (Robbins \& Judge.2013; Luthans, 2010). Strategic choice on the other hand draws from economic and strategic perspectives so as to explain the economic justification for the specific choices made by TMTs. The construct of velocity has drawn from organizational theory that has undertaken to study the imperative of environment as a contingent factor that will influence both firm structure and strategy (Child, 1997; Robbins, 2004; Daft, 2007).

Secondly, the discussions point at possible complementarities that exist among the constructs in describing firm strategic behaviour. The role of TMT diversity has been linked to strategic decisions that should optimize firm performance. The strategic decision in this case seems to reflect the strategic choice where the concentration is on how of the choice and the particular type of choice. The purpose of the choice is addressed by the construct of velocity that calls for environmental analysis so as to generate a choice that fits the organization into the context demanded by the industry conditions that display the nature of industry velocity prevailing in each industry, which can be low or high.

The third issue that this literature points to regards the disjointed manner in which the literature has treated the constructs. Even though areas of complimentarity are clear, the fact that multiple disciplines have contributed to their understanding, the multiple disciplinary boundaries seem to have contributed to the prevailing situation in which the possible linkages among the constructs have not been brought out except in the case where attempts have been made to link TMT Diversity with performance. As a result, extant empirical work seems to have ignored this possibility and failed to mount investigations that would examine interconnectedness of these constructs drawing on the existing theoretical complimentarity. Several empirical attempts have used the three constructs to play different roles in research. For example, Knight, Pearce, Smith, Olian, Sims, Smith and Flood (1999) tried to link TMT diversity with strategic consensus. Liu, Uchida and Yang (2011) linked TMT diversity and firm performance. Geletkanyez and Hambrick (1993) linked the external ties (networks) of TMT and strategic choice and firm performance. Nutt (2010) did an empirical test on the Thompson Model of strategic choice in USA. Further, Mutuku (2013) linked TMT diversity, quality decisions and performance of central banks in Kenya and Rumana and Mutuku (2017) researched on age and cultural diversity effect on the performance of quality control in organizations and found a positive linkage on both aspects to firm performance.

Lastly, arising from the multidisciplinary repository of literature underpinning the constructs, there is needed to trace the constructs to their theoretical roots so as to compare the conceptual understanding with the postulates of relevant theories. Doing so accords scholarship in strategic management an opportunity to thoroughly examine each construct, expand the scope of understanding and compliment the conceptual understanding with contributions that arise from the theories especially in generating operational indicators.

\subsection{Review of Theories}

The foregoing conceptual reviews have provided minimal theoretical underpinnings for constructs on TMT diversity, Strategic choice and firm performance. The constructs therefore require a detailed theoretical perspective obtained from a wider range of theories. This paper was based on Upper echelon theory, Resource Based View, contingency theory, institutional theory and attention based view. These theories provide a link on TMT diversity, strategic choice and firm performance relationship in various firm velocity levels. None of the theories highlights on the three variables in totality.

\subsubsection{Upper Echelon Theory}

Cyert and March (1963) were the first scholars to note the essence of TMT during their study on dominant coalition. Years later, Hambrick and Mason in 1984 advanced the upper echelons theory and are regarded as the main proponents of the theory. They categorized the theory as a behavioral approach that expounds on the significant role of TMT on purpose, direction and overall performance of the firm. They additionally argued that characteristics and cognitive bases of TMT affected the effectiveness of the firm strategic choices. The theory was further advanced by Carpenter and Sanders (2002) who explained that firm outcomes were reflections of the values and cognitive bases of the powerful TMT in the firm. The TMT were powerful actors on various roles of the firm. The upper echelons theory highlights on two main constructs of managerial cognitions and TMT characteristics. The TMT characteristics constructs have been emphasised more than managerial cognitions.

The Upper echelon theory expounds on the characteristics of age, functional background and educational experiences and how they induce the executive's interpretation of the situations both internal and external. It further facilitates the formulation of best strategic alternatives. The attitudes, skills, values and cognition of the TMT were highlighted 
as influencers of strategic choices by the firm executives (Hambrick \& Mason, 1984). These varying characteristics of the TMT form the TMT diversity. TMT diversity is basically operationalised in terms of observable demographic factors that include; educational background, functional background, team size, team tenure, gender. They serve as substitutes for psychological characteristics of self efficacy, emotional stability and locus of control that influence strategic choices and firm performance (Hambrick \& Mason, 1984).

Upper echelons theory provides a focal point between individual-level TMT characteristics and organizational-level outcomes. Upper Echelons Theory advocates that strategic choices, firm's results and performance levels are predicted by the TMT's background characteristics. This is not the case at all times because other factors; internal or external play part towards the firm outcomes. In addition upper echelons theory gives more credit to the TMT unlike the other firm members who play a critical part towards performance of the firm. On this aspect, the upper echelons theory focused majorly on the top executive; CEO unlike other top management team members. This might lead to challenges within the firm towards attainment of goals.

\subsubsection{Theory of Strategic Choice}

The theory is traced to studies in organization theory by John Child (Child, 1997). The theory describes the role that leaders or leading groups play in influencing an organization through making choices in a dynamic political process. It emphasizes the agency of individuals and groups within organizations to make choices sometimes serving their own ends that dynamically influenced the development of those organizations.

Strategic choice perspective originally advanced as a corrective to the view that the way in which organizations are designed and structured is determined by their operational contingencies. This view overlooked the way in which the leaders of organizations were able in practice to influence organizational forms to suit their own preferences. It drew attention to the active role of leading groups who had the power to influence the structures of their organizations through an essentially political process. It was borne out of research that investigated components of organization structure and their relationship with situational variables on a systematic comparative basis which had relied on a structural determinism perspective embraced in the Aston School that assumed that contextual factors imposed certain constraints upon the structural choices managers could make without incurring unacceptable performance costs. The justifying argument was that if an organization is not adapted to its context then opportunities are lost, costs rise and maintenance of the organization is threatened and thus tended to stress more on environmental selection rather than selection of the environment. The strategic choice perspective therefore considered the deterministic view to be inadequate because of its failure to give due attention to the agency of choice by those who have the power to direct the organization. In advancing this logic, the theory offered a description on the construct of strategic choice, the manner in which the choice is exercised which requires understanding of the nature of agency and choice.

The construct of strategic choice was defined as the process whereby power holders within organizations decide upon courses of strategic action. This description by Child (1997) extended to include focus on the environment within which the organization is operating to the standards of performance against which the pressure of economic constraints has to be evaluated and to the design of the organization structure itself because it appreciated the reality that strategic choices are made through initiatives within the network of internal and external organizational relationships through proaction as well as reaction. In such a setting, effective strategic choice requires the exercise of power and is therefore an essentially political phenomenon.

Exercise of strategic choice by organizational decision makers was defined to refer to a process in which the first stage is their evaluation of the organization's position, the expectations placed on it by external resource, the trend of the relevant external events, the organization's recent performance, and how comfortable the decision makers are with its internal configurations. The theory argues that the decision makers' prior values, experience and training are assumed to colour this evaluation in some degree. The evaluation phase is followed by choice of objectives which is reflected in strategic actions decided on. Three key issues arising from the strategic choice analysis concern: (i) the nature of agency and choice which centers around creation of structures that end up limiting organizations as exhibited by the limitations brought about by organization cultures; (ii) actions determination, which is premised on the fact that actions are selected according to inbuilt preferences and information processing systems of the actors' mindsets which invites the role of the actors' interpretative process raising the role and significance of the attendant managerial cognitions. The mindset tends towards stability which inhibits choices that are adaptive to new circumstances. To address this risk of stability, Child (1997) suggested adoption of the term Strategic Issues Diagnosis (SID) which refers to the cognitive process through which decision makers form interpretation about organizational events, developments and trends and encompasses both individual and group think levels. It takes two 
forms: Automatic SID which represents the in built cognitive mechanism and Active SID which represents the intentional and conscious information search and analysis so as to allow for multiple interpretation of an issue.

\subsubsection{OODA Loop Model}

The model was proposed by Colonel John Boyd. According to Wilson, Wilcox and Richards (2004) strategic choice involves the process of making a decision based on the OODA Loop approach which involves the process of Observe, Orient, Decide and Act (OODA). They pointed that the TMT is expected to make observation of the environment both internally and externally and orient themselves towards the observed environments. Then a decision is made based on the orientation. The decision part forms the strategic choice. Based on the decisions made the firm acts in response and the cycle repeat itself. This approach involves the continuous process of Observe, Orient, Decide and Act (OODA) and emphasizes on agility during decision making. The faster the decision making; OODA loop, the higher the degree of initiative against the opponent. The OODA loop has its basis in the military as an efficient decision making tool at all levels; strategic, operational and tactical. Strategic choice has not fully emphasized this aspect in non military institutions. Hambrick (2007) further suggested that strategic decision making within firms was recognized as a team shared effort that involved collective thinking and capabilities of the entire TMT.

Observation entails a clear situational awareness of the internal and external stimuli that affect the firm in its operations towards performance. The political, social, economic, environmental, technological and legal changes form part of the environment. Orientation stage involves the adjustment that the firm must take so as to be able to gain more information about the observed environmental changes. The TMT must be well experienced and intelligent for proper orientation. Decision involves the use of mental models in selecting the best alternative or course of action that will act as a response to the stimuli. The TMT main responsibility is to make the best decisions or strategic choices for the firm so as to remain competitive in the industry. Action involves the implementation of the strategic choice taken by the firm in a timely and effective manner. Well executed actions bring about improved firm performance.

Firms must compete in the industry with their opponents for their survival at all times. The rate of change in the decisions is very fast and this calls for more accurate and real time intelligence which is not easily available among the TMT. The turbulent environment calls for rapid and continous changes in the speed of the OODA loop. This further, affects the TMT balance between exploitation and exploration strategic choices. The approach has not been mostly used in business and thus a weakness that needs to be exploited.

\subsubsection{Attention Based View}

Ocasio is the main proponent of attention based view. Corner, Kinicki and Keats, (1994) stated that firms are systems of structurally distributed attention. Later, this theory according to Ocasio, 1997; Hoffman and Ocasio, (2001); Ocasio and Joseph, (2005) viewed management attention as an important resource for decision-making and it depicted a firm as a system of structurally distributed attention. Attention is the selective process of noticing, encoding, interpreting and focusing of time and effort towards issues and answers according to Ocasio (1997). The attention of the individuals is based on the situations or events they find themselves in. In addition to that, Ocasio, (1995) had proposed that social constructs helped in understanding how firms behaved in their environment. The response by firms to problems is based on firms' response structures which are socially constructed based on attention. Attention plays a vital role towards the end results of the firm and making quality of decisions. Focus of attention is divided into three principles; focus of attention, situated attention and structural distribution of attention according to advancements on cognition by sociologists.

Managers make their decisions based on their area of focus and attention. Ocasio, (1997); Simon, (1947/1997) argued that managers attend to limited issues that influence their decision making. Choosing the best course to focus on is a challenge to many managers because the various information that the TMT has to filter for reliable intelligence. Maggitti, Smith, Tesluk, and Katila, (2013) posited that the TMT attention is either internal or external. Attention structures are the basic determinants for organizational behaviour because they provide hints to decision makers on how to respond to environmental stimuli as posited by Ocasio, 1997; Pfeffer \& Salancik, 1978).

Various researches have proved that decision making attention mostly relies on external environment and thus reason most TMT focus on external environment. Time spent on activity is used as a measure of the level of attention according to findings by Bouquet, Morrison, and Birkinshaw, (2009). This differs from team to team. Other groups argue that attention is measured based on the gains the TMT attaches to an activity. The theory is biased more on strategic choice rather than on the three constructs in totality. 


\subsubsection{Institutional Theory}

The key proponents of institutional theory are Meyer and Rowan. According to Meyer, Rowan and DiMaggio, (1991); and Scott, (2007), institutional theory has been concerned with how firms ensure legitimacy in their existence and operations by conforming to rules, regulations and policies in the environment they operate in. Legitimacy is drawn from the rules or laws enacted by the governments, law courts, professional bodies, scripts and other cultural practices exert conformance pressures (DiMaggio \& Powell 1983, 1991). They further propagated the concept of isomorphism, whereby firms operate in tandem with laid down norms.

Institutional theory has evolved over time. Scott categorized the three main types of institutions: regulatory, normative and cognitive. The regulatory pillar gave incentive and sanction to firms and individuals to regulate their actions (Scott, 2007). In contrast, the normative and cognitive pillars were socially constructed over time and came to be perceived as objective and external to the actors: not as man-made but a natural and factual order (Scott, 1995). The social construct within firms has led to variation in interpretations and thus differences among the TMT. Scott, (1995) in addition argued that institutional theory considers the process by which structures, including schemes, rules, norms and routines, become established as authoritative guidelines for social behaviour. The firm as a social institution is guided by regulations.

Institutional theory shows that firm's behaviours are reactions to market and institutional pressures as well (Greenwood \& Hinings, 1996). Institutional pressures come from external agencies like professional bodies, government, regulation bodies and other firms in the industry among others. These institutional pressures are further affected by economic dynamics and nature of decision making by the TMT. To ensure legitimacy in the eyes of external stakeholders, firms change towards practices that are in tandem with the law despite them not being efficient. McKay, (2001) further posited that firm survival was based on conformity to the external rules and norms. The social expectations have really affected the survival of firms in the industry. Campbell (2007) suggested that the behaviour of firms in a socially responsible way is shaped by institutional theory. This helps in guiding the activities of the TMT. The Top management of the firm needs to have innovation skills for them to be able to sustain the firm in the market.

\subsubsection{Managerial Cognitive Theory}

According to Stimpert,( 1999) review, managerial cognition theory is concerned with the development of a deep understanding of the way in which managers think. Managerial cognition emphasises on the upper echelon theory objective of positioning the manager at the center stage (Eden \& Spender, 1998). This is because the manager is key in the functioning and performance of the organisation. Managerial cognitive theory is rooted in Piaget theory of cognitive development, is a comprehensive theory that addresses the nature and development of human intelligence and later the development of the cognitive theory which explains the mental processes, influenced by both intrinsic and extrinsic factors. This theory explains how different processes that involve learning can be explained by analyzing the mental processes. Cognition is the mental action or process of acquiring knowledge and understanding through experience and senses. According to Stimpert,(1999) review, managerial cognition theory is concerned with the development of a deep understanding of the way in which managers think. The issues on the importance of the managers and the organisation in making sense of situations and events. Sense making involves the intepretation, frames, schemas and assumptions of situations or events (Meindl, Stubbart, \& Porac, 1994).

\subsubsection{The Environmental Velocity Framework}

The framework is based on the concept of Environmental velocity as an important concept characterizing the conditions of organizational environments. The concept was introduced by Bourgeois and Eisenhardt (1988) to the management literature in their study of strategic decision making in the micro computer industry. The role of the concept derives from the perspective that environment is a source of information that managers use to maintain or modify their organizations. Velocity has important implications for organizations, for example, success in high velocity industries is related to fast formal strategic decision making processes, high levels team and process integration, rapid organizational adaptation and fast product innovation and the use of heuristic reasoning processes. It affects how managers interpret their environments. The framework sought to address weaknesses in the previous attempts to treat environmental velocity by use of a singular categorical descriptors most typically as low, moderate and high. Bourgeois and Eisenhardt perspective of velocity identified two dimensions of velocity: change and rate; and multiple dimensions (demand, competitors, technology and regulatory)

In their review of extant research, McCarthy et. al (2010) noted that research has overlooked the dimensionality of the concept of environmental velocity. They therefore proposed a theoretical framework that articulates its 
multidimensionality and by exploring the implications of the framework for understanding the organization-environment relationship. They presented the construct of Environmental velocity as a multidimensional concept based on the argument that environments comprise of multiple dimensions each of which has its own rate and direction of change.

The rate is the amount of change in a dimension of the environment over a specified period of time synonymous with such concepts as pace, speed, clock rate or frequency of change. Direction varies in terms of its degree of continuity and discontinuity. Continuous change represents an extension of past development. Discontinuous change represents a shift in direction and so change in a dimension over time. The dimensions of environmental velocity include demand, competition, technology, regulation and the product dimension.

The proponents in an attempt to describe the relationships among the dimensions suggested that the relationships are explained by three constructs: velocity homology, coupling and regimes. The three concepts are suggested in the framework due to the need to examine differences and relationships among the velocities of different dimensions. Homology refers to the relative similarity among the rates and direction of change of different dimensions, similarities among organizations. It can range from low to high. Coupling refers to the degree to which the velocities of different dimensions are causally connected. It can range from loosely coupled to tightly coupled. Regimes refer to the different patterns of environmental velocity that emerge from variations in velocity homology and velocity coupling.

\subsubsection{Theoretical Issues}

The reviewed literature has brought out several issues. First is a clear demonstration on how the theories anchor the various constructs in their propositions. The upper Echelon theory anchors the construct of TMT Diversity, OODA approach strategic choice, Managerial Cognition theory TMT decision making, velocity framework industry velocity dimensions, strategic choice theory strategic choice and TMT. In addition the theories also demonstrate complementarities in the way they anchor the constructs. The strategic choice theory focuses on choice, TMTs, TMT Cognition and aspects of the external context which has relevance to velocity. The upper echelon theory focuses on TMT diversity and managerial cognition. The managerial cognition theory focuses on TMT and decision making. The OODA Approach ties with multidimensional framework in addressing the question of timing of response to industry velocity; the managerial cognition theory and the upper echelon concur in their focus on the attributes that characterize the demographic and psychological diversity of TMT members; the institutional theory and strategic choice theory address the construct of strategic choice; the attention based view agrees with multidimensional framework on the aspects of choice and sped of execution of the choice.

Besides the complimentarity, the theories also demonstrate a number of weaknesses that scholarship needs to address. The upper echelon theory has been faulted for its bias towards TMT diversity and ignoring the important aspect of TMT cognition.

The theories have been used in various empirical studies and they provide a good foundation for the various constructs. For example Mutuku (2013); Buyl, Boone, \& Matthyssens (2011), used upper echelons theory in studying TMT diversity and firm performance while Ocasio (2011) relied on attention based view to advance on the aspects of firm adaptation and attention. Morales, Carlos and Martin (2009) focused on the role of gender diversity in team performance using Upper Echelons theory while Li, Maggitti, Smith, Tesluk and Katila (2013) in a study linking TMT attention to innovation relied on attention based view theory. Study by Nishii, Gotte and Raver (2007) on the relationship between upper echelon diversity, the adoption of diversity practices and organizational performance found out that that demographic diversity of senior management would be positively associated with the diversity of the workforce, adoption of diversity practices, and power of an organization's diversity officer, and that diversity practices impact organizational performance partially. The study used demographic diversity of senior management as the independent variable and diversity of the workforce, adoption of diversity practices, power of an organization and organizational performance as the dependent variables. Review by Wood and Bandura (1989) on social cognitive theory of organizational management found out those managers begun to form a self-schema of their efficacy through further experience, the performance system is regulated more strongly and intricately through their self-conceptions of managerial efficacy. In the study behavior, cognitive and other personal factors and environment events operated as interacting determinants that influence each other. Induced beliefs and conception of managerial ability strongly affected both managers self regulatory process and their organisational attainments. Stimpert and Duhaime (2008) on the study of managerial cognition and strategic decision making found out that managerial cognition has significant influence on decision making. The study was based on large firms and the dependent variables were executive relationships,executive beliefs and understanding. The dependent variables were 
diversification and decision making. The limitations of the study were that the dominant logics were not well captured, the resp[onse rate was low since it used survey method for data collection.

\section{A Call for a Theoretical Framework}

The purpose of the paper was to examine the existing literature on TMT Diversity with a view to understanding the phenomenon it brings about in organizations and its outcomes identify complementarities among the constructs in the phenomenon and theories and gaps that offer the direction for future research. So far the literature reviewed has been able to provide a comprehensive understanding of each of the constructs as well as their operational indicators. In order to move scholarship forward, there is need to ascertain the validity of the conceptualization that the literature brings out from a practical point of view. This requires that each of the constructs be investigated on an empirical basis in a manner that measures their respective behaviour in a real life situation. A theoretical framework becomes necessary to designate the role of each of the constructs in a defined phenomenon so as to facilitate measurement through operationalization of each construct. According to Kerlinger and Lee (2000) scientists operate in two worlds: world of construct and observation. While the work of the paper has addressed the scientist's world of construct, the move to the next level of observation necessitates that a theoretical framework be suggested so as to provide a bridge between the two worlds.

The required framework needs to be considered as a key component of the scientific expectation in the advancement of knowledge in social science research. Nachmias and Nachmias (2004) lay emphasis on the role of a theory in advancing scientific knowledge and classify a theoretical framework as one of the advanced levels of a theory in which a researcher presents constructs and systematically places constructs in a broad structure that describes categories and makes explicit propositions. Such propositions express relationships between two or more empirical properties that can be subjected to empirical tests to be accepted or rejected. Thus based on this inclination, if the current state of knowledge is to advance to new frontiers, it will require that a theoretical framework is proposed clearly delineating constructs that define the phenomenon of interest and their roles in the phenomenon and propositions advanced in a way that researchers can measure in an empirical investigation.

In terms of the philosophical inclinations that claim to knowledge need justification, the scientific methodology towards advancement of knowledge based on both ontological and epistemological inclinations supports the view that advancement of new knowledge calls for theoretical models (theories) that affirm empirical work. There are debates as to whether theory should come before research or vice versa (Nachmias \& Nachmias, 2004). Proponents of the school of thought supporting theory before research base their argument on the fact that a theoretical framework supports a research study theory by constructing an explicit theory or model, selecting a proposition derived from the theory and modeling for empirical investigation and designing a research project to test propositions. This allows the researcher to examine assumptions, address queries of why and how, permit the researcher to intellectually progress from simply describing phenomenon that has been observed to generalising various aspects of the phenomenon and assist in identifying limits to those generalizations (Wandiga, Kilika, \& James, 2017; Nachmias \& Nachmias, 2004). Thus in consideration of the above observations, the authors are of the view that there is a compelling case for the development of a new model to relate TMT Diversity with strategic choice, industry velocity and firm performance.

\subsection{Proposed Theoretical Framework}

In response to the above call, the authors propose a multidisciplinary based theoretical model that describes the phenomenon emerging from the deployment of TMT Diversity. The proposed model identifies the key pillars in the phenomenon comprising TMT Diversity, Firm Performance, Strategic Choice and Industry Velocity as the key constructs that define the phenomenon. The model conforms to the expectations of theory building (Muthimi \&Kilika, 2018) in not only outlining the constructs but also their respective roles in the phenomenon as shown in Figure 1. 


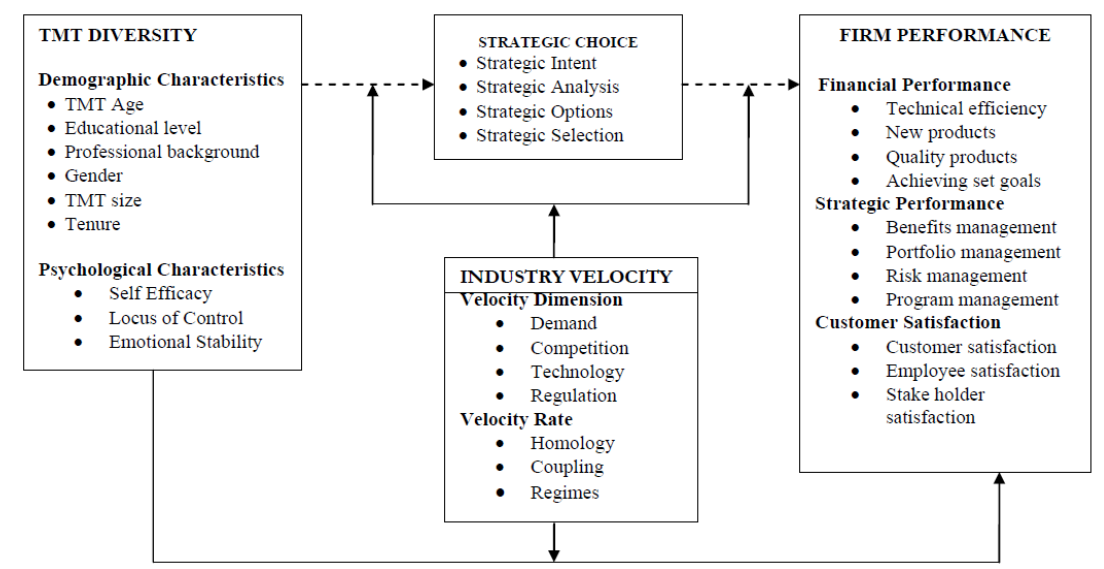

Figure 1. Theoretical model linking TMT diversity and performance in the context of strategic choice and industry velocity

\subsection{TMT Diversity and Firm Performance}

TMT Diversity is depicted in the model as the antecedent factor that sets the phenomenon into motion. TMT Diversity has been operationalized through two broad categories of indicators, namely demographic and psychological dimensions. The various components of demographic form of diversity inject into the systems of an organization the capability for information retrieval and exchange to make decisions, sharing cognitions, innovation, belief system, risk taking behaviors, adaptation to change, decision making speed and time. The psychological dimension on the other hand ushers into the system capabilities for judgment of internal capabilities and ability to make sense of events in the life of an organization owing to the arguments by the proponents of the OODA Loop Model that TMTs are required to make observation of the environment both internally and externally and orient them towards the observation events (Wilson et.al 2004). From the RBV perspective, TMT can be construed to be a form of strategic resource which when deployed in an organization is likely to bring about consequences that will give direction to the firm in pursuit of its desired goals which connect with performance. The construct of TMT diversity is one that has both objective and subjective attributes such that its outcomes can be both quantitative and qualitative respectively. Thus, performance has been operationalized using three forms namely financial, strategic and customer satisfaction indicators. Based on the theoretical arguments on the role of TMTs in giving direction to an organization through pursuit of vision, mission and corporate goals, deployment of TMT Diversity as a strategic resource is proposed to give rise to a corresponding enhanced performance of organizations. The extant theoretical and empirical literatures point to diverse aspects of TMT with association to various components of performance such as educational diversity, age, gender, mental flexibility, gender diversity, self efficacy and locus of control being correlated with relationship with innovation, firm's growth, risk taking behavior, team tenure cohesiveness, conflict resolution, adaptation to change and integration, high capability of facing challenges, and commitment to the firm respectively (Maertz, Bauer, Mosley, Posthuma, \& Campion (2005). We therefore propose that:

Proposition 1: Deployment of the various forms of TMT Diversity will positively affect the various dimensions of a firm's performance.

\subsection{The Role of Strategic Choice}

The construct of strategic choice has been operationalized through the indicators of Strategic Intent, Strategic Analysis, Strategic Options, and Strategic Selection. The process entails decision making in an environment of uncertainty to do a selection of a strategic alternative that offers maximum utility to a firm. In line with this reasoning, Child (1997) considered it as a process, whereby power holders within the organization decide the courses of strategic action including focus on the environment, standards of performance against which pressure of economy constraint has to be evaluated, and is made through proaction and reaction. Child (1997) further argues that the decision makers' prior values, experience and training colour their evaluation to some degree, thus pointing to the potential role that TMT characteristics are likely to play in a firm's strategic choice. This reasoning gains more support as one considers ideas borrowed from the agency perspective based on the possibility of influence of agency on choice during the decision, whereby actions are selected according to inbuilt preference and information 
processing system of the actor's mind set. The literature is rich with arguments that tend to link several dimensions of TMT Diversity with firm's decisions such as emotional stability and response to problems, social integration; experience to sound strategic decision making and ability to carry out environmental screening. In view of this identified theoretical link, the authors propose a possible link between the deployment of TMT Diversity and an organization's strategic choice. Thus,

Proposition 2a: There is a correlation between the deployment of the various forms of TMT Diversity and the Strategic Choice adopted by the firm.

The essence of the strategic choice made by the organization is to optimize on the opportunities identified in the external environment of the firm. In line with the requirement to attain a strategic fit between a firm and the requirements of its external environment, TMTs as decision makers that give direction to a firm will result to choices that will enhance the ability of a firm to fit in its external environment so as to provide a strong basis for sustaining performance. Thus the strategic choice made by the TMTs is seen as an important factor arising from deployment of the various forms of TMT Diversity suitable to sustain desired levels of firm performance. We therefore propose that:

Proposition 2b: Even though deployments of the various forms of TMT Diversity affects the performance of a firm, the degree of this effect is dependent upon the strategic choice selected by the TMT Members.

\subsection{Role of Industry Velocity}

The deployment of the various forms of TMT Diversity is within the constraints of the dynamics of the external environment an organization operates in. TMT members are interested in the concept of velocity because it is connected with variation in the emergence of business opportunities. It is in the same perspective that the construct of velocity has been theoretically conceptualized in reference to the rate at which new opportunities emerge and disappear in an industry and for a firm it is determined by stability and resistance to shock. The proposed model conceptualized the construct of Industry Velocity in terms of two broad dimensions, namely Velocity Dimension (Demand, Competition, Technology, and Regulation) and Velocity Rate (Homology, Coupling, Regimes).

Literature argues that success in high velocity environment is related to fast, formal, strategic decision making process and use of heuristic reasoning process. As a result of this, TMTs need to build a firm collective cognition and perceived environmental velocity. TMTs collectively construct their environmental velocity through their social network, collective assumptions and environmental scanning approaches by which firms develop sense making approaches for effectively understanding and dealing with the dynamics in high velocity environments. The means of dealing with the environment is through the strategic choices that TMTs make. Bennett and Lemoine, (2014) pointed at the possibility that aspects of the environment bringing about velocity can affect the manner in which organizations respond to their environments. Thus the TMTs strategic choice will largely rest upon the TMTs interpretation of the state of industry velocity faced by a firm. On this logic, we propose that:

Proposition 3a: The relationship between deployment of the various forms of TMT Diversity and the Strategic Choices TMT members make is moderated by the TMT Cognitions on the level of industry velocity facing each firm.

In line with the above argument, industry velocity has been related with the speed of response or adaptation because of its influence on the TMTs interpretation of their environments. Child (1997) observed that ordinarily managerial mind set tends towards stability which inhibits choices that are adaptive to new circumstances. In order to avoid risks under this setting, Child proposed adoption of SID by which decision makers form interpretation about organizational events, developments and trends, thus leading to two forms of Strategic issues Diagnosis (SID): Automatic SID and Active SID. The active SID that embraces an intentional and conscious information search and analysis so as to allow for multiple interpretation of an issue is what has been proposed for adoption by TMTs that focus on attaining a strategic fit with their environments. Thus well diversified TMTs will adopt this form of diagnosis so as to position a firm to appropriately respond to variations in the emergence of opportunities so as not to dilute the earned state of competitiveness in its market. Thus, the level of velocity is seen to condition the nature of relationship linking the performance of the firm with both the choice that responds to the velocity and the deployment of the TMT Diversity itself (Brouthers et al, 2000; Goll \& Rasheed, 2005). Therefore, we propose that:

Proposition 3b: The mediated effect of Strategic Choice on the relationship between deployment of the various forms of TMT Diversity and firm performance will be moderated by the TMT Cognition on the level of industry velocity.

Proposition 3c: The level of Industry Velocity moderates the relationship between the deployment of the various forms of TMT Diversity and Performance of the firm. 


\section{Conclusion and Direction for Further Research}

The purpose of this theoretical paper was to review both extant theoretical and empirical literature, identify existing gaps in the phenomenon of TMT diversity, strategic choice, industry velocity and firm performance and finally suggest a theoretical framework providing propositions addressing the identified gaps. Towards this, the paper has presented a comprehensive review of theoretical, conceptual and empirical literature pertaining to the constructs underpinning the study. The state of the art of the literature was demonstrated through an highlight of the current understanding, how it has been applied in research as supported by the relevant extant theories. In addition, the issues arising from the extant literature were clearly pointed out and led to identification of key knowledge gaps that form the basis for continuing dialogue on extending the work from its current state to new frontiers. The paper used several bases to present a case for a new theoretical model that demonstrates the emerging phenomenon involving identified constructs, their indicators and possible relationships. The proposed theoretical framework has presented these relationships in the form of propositions that future research can translate into hypotheses in an empirical investigation.

In presenting this paper, the authors however acknowledge certain limitations. First, the literature even though rich in its origin and focus was drawn from a few disciplines that are considered relevant to enhancing understanding of the strategic management phenomenon in organizations. The authors invite suggestions from the multidisciplinary body of knowledge in organizational studies that would further enrich this continuing discussion on the deployment of TMT Diversity and its emergent outcomes. Secondly, the empirical studies reported were indicated that they face limitations in terms of their scope of conceptualization due to the inherent limitations in the depth of conceptual rigor in the design of the studies. Thirdly, the propositions the study makes are yet to be empirically validated. The authors therefore call on future research to consider translating the proposed theoretical framework into a conceptual framework for guiding empirical investigations that use the indicators of the constructs for measurement in a research instrument so as to validate the claims made by the propositions using factual data.

\section{References}

Aaker, D. A. (2008). Marketing in a silo world: The new CMO challenge. California Management Review, 51(1), 144-156. https://doi.org/10.2307/41166473

Ackermann, F., \& Eden, C. (2011). Strategic management of stakeholders: Theory and practice. Long Range Planning, 44(3), 179-196. https://doi.org/10.1016/j.lrp.2010.08.001

Agle, B. R., Mitchell, R. K., \& Sonnenfeld, J. A. (1999). Who matters to CEOs? An investigation of stakeholder attributes and salience, corporate performance, and CEO values. Academy of Management Journal, 42(5), 507-525.

Amini, S. (2013). The amount of raised capital by small IPOs: Spatial effect on the UK alternative investment market. International Journal of Entrepreneurial Behavior \& Research, 19(3), 344-358. https://doi.org/10.1108/13552551311330219

Bandura, A. (1997). Self-efficacy: The exercise of control. Macmillan.

Barney, J. B. (1991). Firm resources and sustained competitive advantage. Journal of Management, 17(1), 99-120. https://doi.org/10.1177/014920639101700108

Barney, J. B. (1997). Gaining and Sustaining Competitive Advantage. Addison - Wesley, Reading, M A.

Bass, B. M., \& Stogdill, R. M. (1990). Bass \& Stogdill's handbook of leadership: Theory, research, and managerial applications. Simon and Schuster.

Bolla, K. I., Brown, K., Eldreth, D., Tate, K., \& Cadet, J. L. (2002). Dose-related neurocognitive effects of marijuana use. Neurology, 59(9), 1337-1343. https://doi.org/10.1212/01.WNL.0000031422.66442.49

Bouquet, C., Morrison, A., \& Birkinshaw, J. (2009). International attention and multinational enterprise performance. Journal of International Business Studies, 40(1), 108-131. https://doi.org/10.1057/jibs.2008.64

Bowman, C., \& Ambrosini, V. (2003). How the resource-based and the dynamic capability views of the firm inform corporate-level strategy. British Journal of Management, 14(4), 289-303. https://doi.org/10.1111/j.1467-8551.2003.00380.x

Bozec, R., Dia, M., \& Bozec, Y. (2010). Governance performance relationship: A Re-examination Using Technical Efficiency Measures. British Journal of Management, 21(3), 684-700. https://doi.org/10.1111/j.1467-8551.2008.00624.x 
Brouthers, K. D., \& Nakos, G. (2004). SME entry mode choice and performance: A transaction cost perspective. Entrepreneurship Theory and Practice, 28(3), 229-247. https://doi.org/10.1111/j.1540-6520.2004.00041.x

Bunderson, J. S., \& Sutcliffe, K. M. (2003). Management team learning orientation and business unit performance. Journal of Applied Psychology, 88(3), 552. https://doi.org/10.1037/0021-9010.88.3.552

Campbell, J. L. (2007). Why would corporations behave in socially responsible ways? An institutional theory of corporate social responsibility. Academy of Management Review, 32(3), 946-967. https://doi.org/10.5465/amr.2007.25275684

Cannella, A. A., Park, J. H., \& Lee, H. U. (2008). Top management team functional background diversity and firm performance: Examining the roles of team member collocation and environmental uncertainty. Academy of Management Journal, 51(4), 768-784.

Child, J. (1972). Organizational structure, environment, and performance: The role of strategic choice. Sociology, 6(1), 1-22. https://doi.org/10.1177/003803857200600101

Corner, P. D., Kinicki, A. J., \& Keats, B. W. (1994). Integrating organizational and individual information processing perspectives on choice. Organization Science, 5(3), 294-308. https://doi.org/10.1287/orsc.5.3.294

Curral, L. A., Forrester, R. H., Dawson, J. F., \& West, M. A. (2001). It's what you do and the way that you do it: Team task, team size, and innovation-related group processes. European Journal of Work and Organizational Psychology, 10(2), 187-204. https://doi.org/10.1080/13594320143000627

Cyert, R. M., \& March, J. G. (1963). A behavioral theory of the firm. Englewood Cliffs, 2, 169-187.

DiMaggio, P., \& Powell, W. W. (1983). The iron cage revisited: Collective rationality and institutional isomorphism in organizational fields. American Sociological Review, 48(2), 147-160. https://doi.org/10.2307/2095101

Donaldson, L. (2001). The contingency theory of organisations. Sage, Thousand Oaks. https://doi.org/10.4135/9781452229249

Eisenhardt, K. M., \& Martin, J. A. (2000). Dynamic capabilities: What are they. Strategic Management Journal, 1105-1121. https://doi.org/10.1002/1097-0266(200010/11)21:10/11<1105::AID-SMJ133>3.0.CO;2-E

Finkelstein, S., \& Hambrick, D. C. (1990). Top management-team tenure and organizational outcomes: The contingent role of managerial discretion. Administrative Science Quarterly, 484-503. https://doi.org/10.2307/2393314

Finkelstein, S., Hambrick, D. C., \& Cannella, A. (1996). Strategic leadership. St. Paul Minn West.

Frankfort-Nachmias, C., \& Nachmias, D. (2004). Research Method in social sciences. London. Arnold

Frink, D. D., Robinson, R. K., Reithel, B., Arthur, M. M., Ammeter, A. P., Ferris, G. R., ... Morrisette, H. S. (2003). Gender demography and organization performance: A two-study investigation with convergence. Group \& Organization Management, 28(1), 127-147. https://doi.org/10.1177/1059601102250025

Geletkanycz, M. A., \& Hambrick, D. C. (1997). The external ties of top executives: Implications for strategic choice and performance. Administrative Science Quarterly, 654-681. https://doi.org/10.2307/2393653

Haleblian, J., \& Finkelstein, S. (1993). Top management team size, CEO dominance, and firm performance: The moderating roles of environmental turbulence and discretion. Academy of Management Journal, 36(4), 844-863.

Hambrick, D. C., \& Mason, P. A. (1984), Upper echelons: The organization as a reflection of its top managers. Academy of Management Review, 9(2), 193-206. https://doi.org/10.5465/amr.1984.4277628

Hambrick, D. C. (2007). Upper echelons theory: An update. Academy of Management Review, 32(2), 334-343. https://doi.org/10.5465/amr.2007.24345254

Hambrick, D. C., Finkelstein, S., \& Mooney, A. C. (2005). Executive job demands: New insights for explaining strategic decisions and leader behaviors. Academy of Management Review, 30(3), 472-491. https://doi.org/10.5465/amr.2005.17293355

Herzallah, A., Gutierrez-Gutierrez, L. J., \& Munoz Rosas, J. F. (2017). Quality ambidexterity, competitive strategies, and financial performance: An empirical study in industrial firms. International Journal of Operations \& Production Management, 37(10), 1496-1519. https://doi.org/10.1108/IJOPM-01-2016-0053

Hofer, C. W., \& Schendel, D. (1978). Strategy formulation: Analytical concepts. St. Paul: West Pub. Co. 
Hoffman, A. J., \& Ocasio, W. (2001). Not all events are attended equally: Toward a middle-range theory of industry attention to external events. Organization Science, 12(4), 414-434. https://doi.org/10.1287/orsc.12.4.414.10639

Irungu, S. M. (2007). The effect of top management teams on the performance of publicly quoted companies in Kenya. Unpublished PhD Thesis, University of Nairobi, Kenya.

Kaplan, R. S., \& Norton, D. P. (1992). The balanced scorecard measures that drive performance. Harvard Business Review.

Kaplan, R. S., \& Norton, D. P. (1996). The balance scorecard. The Harvard Business School Press.

Kaplan, R. S., \& Norton, D. P. (2001). Transforming the balanced scorecard from performance measurement to strategic management: Part I. Accounting Horizons, 15(1), 87-104. https://doi.org/10.2308/acch.2001.15.1.87

Kaplan, R. S., Norton, D. P., \& Rugelsjoen, B. (2010). Managing alliances with the balanced scorecard. Harvard Business Review, 88(1), 114-120.

Katz, R. (1982). The effects of group longevity on project communication and performance. Administrative Science Quarterly, 81-104. https://doi.org/10.2307/2392547

Keck, S. L. (1991). Top management team structure: does it matter anyway?. Academy of Management Meeting, Miami, FL.

Kilduff, M., Angelmar, R., \& Mehra, A. (2000). Top management-team diversity and firm performance: Examining the role of cognitions. Organization Science, 11(1), 21-34. https://doi.org/10.1287/orsc.11.1.21.12569

Kinuu, D. (2014). Top management team psychological characteristics, institutional environment, team processes and performance of companies listed in Nairobi securities exchange. Unpublished Ph. D. Thesis, University of Nairobi.

Knight, D., Pearce, C. L., Smith, K. G., Olian, J. D., Sims, H. P., Smith, K. A., \& Flood, P. (1999). Top management team diversity, group process, and strategic consensus. Strategic Management Journal, 445-465. https://doi.org/10.1002/(SICI)1097-0266(199905)20:5<445::AID-SMJ27>3.0.CO;2-V

Li, Q., Maggitti, P. G., Smith, K. G., Tesluk, P. E., \& Katila, R. (2013). Top management attention to innovation: The role of search selection and intensity in new product introductions. Academy of Management Journal, 56(3), 893-916. https://doi.org/10.5465/amj.2010.0844

Liu, C., Uchida, K., \& Yang, Y. (2012). Corporate governance and firm value during the global financial crisis: Evidence from China. International Review of Financial Analysis, 21, 70-80. https://doi.org/10.1016/j.irfa.2011.11.002

Luthans, F. (2010). Organizational Behavior (12th ed.). Singapore: McGraw-Hill.

Machuki, V. N., \& Aosa, E. (2011). The influence of the external environment on the performance of publicly quoted companies in Kenya. Prime Journals, Business Administration and Management (BAM), 1(7), 205-218.

Machuki, V. N., Aosa, E. O., Letting, D., \& Nicholas, K. (2012). Firm-level institutions and performance of publicly quoted companies in Kenya. International Journal of Humanities and Social Science, 2(21), 298-312.

Maertz, C. P. Jr., Bauer, T. N., Mosley, D. C. Jr., Posthuma, R. A., \& Campion, M. A. (2005). Predictors of self-efficacy for cognitive ability employment testing. Journal of Business Research, 58(2), 160-167. https://doi.org/10.1016/S0148-2963(03)00111-5

Mahoney J. T., \& Pandian J. R. (1992). The resource-based view within the conversation of strategic management. Strategic Management Journal, 13(5), 363-380. https://doi.org/10.1002/smj.4250130505

Mason, R. B. (2007). The external environment's effect on management and strategy: a complexity theory approach. Management Decision, 45(1), 10-28. https://doi.org/10.1108/00251740710718935

McKay, R. B. (2001). Organizational responses to an environmental bill of rights. Organization Studies, 22(4), 625-658. https://doi.org/10.1177/0170840601224004

Menz, M. (2012). Functional top management team members: A review, synthesis, and research agenda. Journal of Management, 38(1), 45-80. https://doi.org/10.1177/0149206311421830

Meyer, J. W., Rowan, B., Powell, W. W., \& DiMaggio, P. J. (1991). The new institutionalism in organizational analysis. The New Institutionalism in Organizational Analysis, 41-62. 
Miles, R. E., Snow, C. C., Meyer, A. D., \& Coleman, H. J. (1978). Organizational strategy, structure, and process. Academy of Management Review, 3(3), 546-562. https://doi.org/10.5465/amr.1978.4305755

Mintzberg, H. (2000). The rise and fall of strategic planning. Pearson Education.

Mintzberg, H., Raisinghani, D., \& Theoret, A. (1976). The structure of" unstructured" decision processes. Administrative Science Quarterly, 246-275. https://doi.org/10.2307/2392045

Muchemi, A. W. (2013). Top management team diversity and performance of commercial banks in Kenya. Unpublished PhD Thesis, University of Nairobi.

Murray, J. L. (1989). Al-V (aluminum-vanadium). Bulletin of Alloy Phase Diagrams, 10(4), 351-357. https://doi.org/10.1007/BF02877591

Muthimi, J. K., \& Kilika, J. M. (2018). Leadership Strategy, Behavioural Focus and Firm Performance: A Review of Literature. International Business Research; 11(11), 143-163.

Nadkarmi, S., \& Barr, P. S. (2008). Environmental context, managerial cognition and strategic action: an integrated view. Strategic Management Journal, 29, 1395-1427. https://doi.org/10.1002/smj.717

Nadkarni, S., \& Narayanan, V. K. (2007). Strategic schemas, strategic flexibility, and firm performance: The contingent role of industry clockspeed. Strategic Management Journal, 28(3), 243-270. https://doi.org/10.1002/smj.576

Neely, A. (1999). The performance measurement revolution: why now and what next?. International Journal of Operations \& Production Management, 19(2), 205-228. https://doi.org/10.1108/01443579910247437

Nishii, L. H., Gotte, A., \& Raver, J. L. (2007). Upper echelon theory revisited: The relationship between upper echelon diversity, the adoption of diversity practices, and organizational performance.

Norton, D. P. (1999). The Balanced Scorecard: Participant" s Workbook.

Nutt, P. C. (2010). An Empirical Test of Thompson's Model of Strategic Choice. International Journal of Business, 15(2), 159.

Ocasio, W. (1997). Towards an attention-based view of the firm. Strategic Management Journal, 187-206. https://doi.org/10.1002/(SICI)1097-0266(199707)18:1+<187::AID-SMJ936>3.3.CO;2-B

Ocasio, W., \& Joseph, J. (2005). An attention-based theory of strategy formulation: Linking micro-and macro perspectives in strategy processes. Strategy Process (pp. 39-61). Emerald Group Publishing Limited. https://doi.org/10.1016/S0742-3322(05)22002-8

Oduor, B. O., \& Kilika, J. M. (2018). TMT Diversity, Decision Quality, and Service Sector Firm Performance: A Research Agenda. Journal of Management and Strategy, 9(2). https://doi.org/10.5430/jms.v9n2p34

Pearce, J. A., \& Robinson R. B. (1997). Strategic Management: Formulation, Implementation, and Control. Irwin/McGraw-Hill.

Penrose, E. T. (2009). The Theory of the Growth of the Firm. Oxford University Press.

Prahalad, C. K., \& Bettis, R. A. (1986). The dominant logic: A new linkage between diversity and performance. Strategic Management Journal, 7(6), 485-501. https://doi.org/10.1002/smj.4250070602

Richard, O. C., \& Shelor, R. M. (2002). Linking top management team age heterogeneity to firm performance: Juxtaposing two mid-range theories. International Journal of Human Resource Management, 13(6), 958-974. https://doi.org/10.1080/09585190210134309

Robbins, S. P. (1986). Organizational Behavior, Concepts, Controversies and Applications (3rd ed.). New Jersey: Prentice-Hall.

Robbins, S. P. (2004). Organization Theory: Structure, Design, and Applications (3rd ed.). Englewood Cliffs, NJ: Prentice Hall.

Robbins, S. P., \& Judge, T. (2013). Essentials of Organizational Behavior (12th ed.). New Delhi: Prentice Hall.

Rumana, A. A., \& Mutuku, C. (2017). Effect of Age and Culture Diversity on the Performance of Quality Control Organizations in Nairobi County, Kenya. Journal of Strategic Management, 1(2), 1-13.

Rumelt, R. P. (1984). Towards a strategic theory of the firm. Competitive Strategic Management, 556-570. 
Sanchez, H., \& Robert, B. (2010). Measuring portfolio strategic performance using key performance indicators. Project Management Journal, 41(5), 64-73. https://doi.org/10.1002/pmj.20165

Saunders, M. N. (2011). Research Methods for Business Students, 5/e. Pearson Education India.

Saunders, M., Lewis, P., Thornhill, A., \& Wilson, J. (2009). Business research methods. Financial Times. Prentice Hall: London.

Spector, P. E. (1982). Behavior in organizations as a function of employee's locus of control. Psychological Bulletin, 91(3), 482. https://doi.org/10.1037/0033-2909.91.3.482

Surroca, J., Tribó, J. A., \& Waddock, S. (2010). Corporate responsibility and financial performance: The role of intangible resources. Strategic Management Journal, 31(5), 463-490. https://doi.org/10.1002/smj.820

Tan, J. T. (2002). Miles \& Snow strategic typology and its current relevance: An empirical study in Singapore. Academy of Strategic Management Journal, 1, 93.

Teece, D. J., Pisano, G., \& Shuen, A. (1997). PIAA Ex. O-102-DP. Strategic Management Journal, 18(7), 509-533. https://doi.org/10.1002/(SICI)1097-0266(199708)18:7<509::AID-SMJ882>3.0.CO;2-Z

Teece, D. J., Pisano, G., \& Shuen, A. (1999). Dynamic capabilities and strategic management. Knowledge and strategy (pp. 77-115). https://doi.org/10.1016/B978-0-7506-7088-3.50009-7

Tihanyi, L., Ellstrand, A. E., Daily, C. M., \& Dalton, D. R. (2000). Composition of the top management team and firm international diversification. Journal of Management, 26(6), 1157-1177. https://doi.org/10.1177/014920630002600605

Tony, G. (2000). Strategic Choice. Management Quarterly (part 8). Retrieved August 8, 2018, from https://www.icaew.com/-/media/corporate/archive/files/technical/business-and-financial-management/businessstrategy/general-strategy/strategic-choice-mq8.ashx?la=en

Wilson, G. I., Wilcox, G., \& Richards, C. (2004). Fourth Generation Warfare \& OODA Loop Implications of the Iraqi Insurgency. Retrieved May 7, 2010, from Smartpei.typepad.com

Wood, R., \& Bandura, A. (1989). Social cognitive theory of organizational management. Academy of Management Review, 14(3), 361-384. https://doi.org/10.5465/amr.1989.4279067 